\section{Kidney \\ Blood Pressure Research}

Kidney Blood Press Res 2013;37:557-566

DOI: $10.1159 / 000355736$
Published online: November 26, 2013

Accepted: September 17, 2013 NonCommercial 3.0 Unported license (CC BY-NC) (www.karger.com/OA-license), applicable to the online version of the article only. Distribution permitted for non-commercial purposes only.

\title{
Eplerenone-Mediated Aldosterone Blockade Prevents Renal Fibrosis by Reducing Renal Inflammation, Interstitial Cell Proliferation and Oxidative Stress
}

\author{
Hui Chen ${ }^{\mathrm{a}}$ Feng Sun ${ }^{\mathrm{b}}$ Xiaoshi Zhong ${ }^{\mathrm{a}}$ Yuebin Shao $^{\mathrm{a}}$ Ashio Yoshimura $^{\mathrm{c}}$ \\ Yan Liu ${ }^{a}$
}

\begin{abstract}
aDepartment of internal medicine, Guangzhou City Red Cross Hospital, Guangdong Province Guangzhou City 510220, China; ${ }^{b}$ Department of Anus \& Intestine Surgery, The First Affiliated Hospital of Guangzhou University of Chinese Medicine, Guangdong Province Guangzhou City, 510405, China; 'Division of Nephrology, Department of Medicine, Showa University Fujigaoka Hospital, 1-30 Fujigaoka, Aobaku, Yokohama 227-8501, Japan
\end{abstract}

\section{Key Words}

Eplerenone $\cdot$ Unilateral ureteral obstruction - Inflammation - Fibrosis • ED-1 - MCP-1 - PCNA $\cdot \alpha-S M A \cdot 8-O H d G \cdot$ Acrolein

\begin{abstract}
Background/Aims: Prolonged elevation of serum aldosterone leads to renal fibrosis. Inflammation also plays a role in the pathogenesis of renal disease. We used a rat model of interstitial renal fibrosis to test the hypothesis that eplerenone-mediated aldosterone blockade prevents renal fibrosis due to its anti-inflammatory and anti-proliferative effects. Methods: Eplerenone (a selective aldosterone blocker) or vehicle (control), was given to male Wistar rats (50 mg/kg, twice daily) for 7 days before unilateral ureteral obstruction (UUO) and for an additional 28 days after surgery. Body weight, blood pressure, renal histo-morphology, immuno-staining for macrophages, monocyte chemotactic protein-1, proliferating cell nuclear antigen, $\alpha$-smooth muscle actin, and serum and urine markers of renal function and oxidative stress were determined for both groups on 7, 14, and 28 days after surgery. Results: Epleronone had no effect on body weight or blood pressure. However, eplerenone inhibited the development of renal fibrosis, inflammation (macrophage and monocyte infiltration), interstitial cell proliferation, and activation of interstitial cells ( $\alpha$-SMA expression). Epleronone also reduced oxidative stress. Conclusion: The anti-fibrotic effect of eplerenone appears to be unrelated to its effect on blood pressure. Eplerenone inhibits renal inflammation, interstitial cell proliferation, phenotypic changes of interstitial cells, and reduces oxidative stress.
\end{abstract}




\section{Kidney Blood Pressure Research}

Kidney Blood Press Res 2013;37:557-566

\begin{tabular}{l|l}
\hline DOI: $10.1159 / 000355736$ & (C) 2013 S. Karger AG, Basel
\end{tabular}

Published online: November 26, 2013

www.karger.com/kbr

Chen/Sun/Zhong/Shao/Yoshimura/Liu: Eplerenone Suppresses Renal Fibrosis

\section{Introduction}

Aldosterone is a steroid hormone produced by the adrenal gland that increases renal tubular reabsorption of sodium and secretion of potassium. Elevated levels of aldosterone increase blood pressure. Many blood pressure medications interfere with the reninangiotensin system by aldosterone blockade. Eplerenone is a modern anti-hypertensive agent that is a competitive antagonist of the aldosterone receptor [1] and is similar to spironolactone, but has at least 100-fold greater affinity for the aldosterone receptor [2]. Eplerenone is therefore less likely to cause adverse effects that are characteristic of nonselective antagonists, such as gynecomastia, impotence, and menstrual irregularities [3-6].

There is increasing evidence that the renin-angiotensin-aldosterone-system (RAAS) plays an important role in the pathogenesis and progression of renal diseases [7-9]. Previous research indicates that elevated levels of aldosterone promote fibrosis [10-12], leading to renal and cardiovascular dysfunction. Therefore, the reno-protective effect of aldosterone blockade has been attributed to its anti-fibrotic activity. However, the anti-fibrotic effect of aldosterone blockade may be an indirect effect due to its modulation of blood pressure.

Tubulointerstitial inflammation and fibrosis have detrimental effects on renal function, and their presence have negative effects on the prognosis of patients with numerous nephropathies. The presence of inflammation is critical in the pathogenesis of renal interstitial fibrosis [13-15]. Recent evidence indicates that aldosterone has proinflammatory effects on monocytes and macrophages and a proliferative effect in vascular myocardial injury [16]. Thus, aldosterone may have a similar effect on renal interstitial cells. Although angiotensinconverting enzyme inhibitor (ACEI) therapy initially attenuates the release of aldosterone, aldosterone gradually rebounds, reversing the beneficial effects on the kidney [17].

We used a rat model of renal interstitial injury to test the hypothesis that aldosterone blockade prevents renal injury by reducing inflammation, proliferation, and oxidative stress. Therefore, we examined the effect of eplerenone, a modern selective aldosterone blocker, in a rat model of unilateral ureteral obstruction (UUO) by comparison of the blood pressure, renal fibrosis, and inflammation of control and eplerenone groups.

\section{Materials and Methods}

\section{Animals and diets}

Thirty-six male Wistar rats that were 6 weeks old and weighed $\sim 140-160 \mathrm{~g}$ were used in this study. Rats were maintained with standard rat chow and tap water at $22^{\circ} \mathrm{C}$ under a $12 \mathrm{~h}$ light/12 h dark cycle. Animal care followed the criteria of the Ethics Committee for Animal Experimentation of University of Showa of Medicine and the NIH Guidelines for the Care and Use of Laboratory Animals.

\section{Experimental design}

Rats were randomly assigned to receive vehicle (control, $n=18$ ) or eplerenone $(n=18)$ by gastric tube (50 mg/kg, 2 times per day at $10 \mathrm{~h}$ intervals) 7 days before UUO. Treatment with eplerenone or vehicle continued until animal sacrifice on 7 days, 14 days, or 28 days after UUO. Rats of both groups underwent UUO after anaesthesia with sodium pentobarbital injection $(50 \mathrm{mg} / \mathrm{kg})$ or diethyl ether inhalation. The left ureter and kidneys were exposed after a $3 \mathrm{~cm}$ midline incision, and the left ureter was ligated with 3-0 silk next to the uretero-pelvic junction. The incision was closed in two layers with 3-0 silk. Rats were allowed to recover and returned to their cages. On 7, 14, and 28 days following surgery, 6 rats of each group were sacrificed (using the same anaesthesia as previously), the left kidneys were harvested for study, and blood samples were obtained from the aorta for determination of potassium, creatinine, and urea nitrogen. On day 7, $24 \mathrm{~h}$ urine was collected for evaluation of oxidative stress by measurement of 8-hydroxydeoxyguanosine (8-OHdG). Measurement of systolic and diastolic blood pressure was performed every day from day 7 until nephrectomy. 


\section{Kidney Blood Pressure Research}

\section{Histomorphology}

After sacrifice, left kidneys were harvested for assessment of renal cortical interstitial inflammation and fibrosis. For paraffin embedding, half of each kidney was fixed in an acid solution (60\% methanol, 30\% chloroform, $10 \%$ acetic acid) and the other half was fixed in a 10\% of formaldehyde (pH 7.4). Renal sections ( $\sim 4$ m thick) were stained with Masson's trichrome (hematoxylin, scarlet-acid fuchsin, aniline blue dye) for evaluation of interstitial fibrosis and images were evaluated by a computer-analysis system at $\times 200$ (AnalySIS, Soft Imaging System GmbH, Munster, Germany). The percentage of renal cortical interstitial cells that were fibrotic was quantified by a point-counting technique (positive areas/total area) as described previously [18-20]. For each sample, 15-20 non-overlapping interstitial fields were scanned. Digital images were superimposed on a grid, and the number of grid lines overlapping the interstitial blue-staining collagen was recorded. All measurements were performed by a single blinded observer.

\section{Immunohistochemistry}

Immuno-staining for macrophages (ED-1), monocyte chemoattractant protein-1 (MCP-1), proliferating cell nuclear antigen (PCNA), and $\alpha$-smooth muscle actin ( $\alpha$-SMA) were performed on all rat kidneys. Briefly, renal sections $(\sim 4 \mu \mathrm{m}$ thick) were subjected to microwave irradiation in a phosphate buffer to enhance antigen retrieval and then preincubated with 10\% normal rabbit serum (Vector Labs, Burlingame, CA) in Tris-buffered saline (TBS). Then, tissues were incubated with 1:100 monoclonal anti-ED1 antibody (Chemicon International, Temaecula, CA), 1:100 monoclonal anti-MCP-1 antibody (Abcam, Cambridge, UK), 1:100 monoclonal anti-PCNA antibody (MBL, NAGOYA, JAPAN), or 1:100 anti-human SMA (DAKO, Glostrup, Denmark) overnight at $4^{\circ} \mathrm{C}$ in a humidified chamber. Then, sections were incubated with appropriate species-specific secondary antibodies for $30 \mathrm{~min}$ at room temperature. Negative control experiments were routinely performed by replacing the primary antibody with non-specific rat IgG. For each section, 15-20 interstitial fields of renal cortical tissue were examined. The inflammatory infiltrates and fibroses were examined in interstitial fields of renal cortical tissue. All data were evaluated by a single blinded observer using a computer-analysis system at $\times 200$. The number of cells positive for ED- 1 and PCNA was expressed as cells $/ 0.5 \mathrm{~mm}^{2}$. Expression of $\alpha$-SMA and MCP- 1 was quantified by a point-counting technique, as described above. The interstitial black-staining collagen was used for trichrome quantification.

\section{Urinary measurements}

The $24 \mathrm{~h}$ urine was collected on day 7 by use of metabolic cages. Samples were centrifuged at 1600 $\mathrm{rpm}\left(558 \mathrm{~g}\right.$ ) for $6 \mathrm{~min}$ at $22^{\circ} \mathrm{C}$. The presence of 8-OHdG was measured by ELISA using a sandwich enzymelinked immunosorbent assay kit from NOF Corporation (Tokyo, Japan).

\section{Serum and blood pressure measurements}

Blood samples were obtained from the abdominal aorta when rats were under anaesthesia. All blood samples were centrifuged at $3000 \mathrm{rpm}\left(1962 \mathrm{~g}\right.$ ) for $10 \mathrm{~min}$ at $22^{\circ} \mathrm{C}$. Serum potassium, creatinine, and urea nitrogen were measured. Systolic and diastolic blood pressure was measured by tail plethysmography in conscious rats every day from day-7 until nephrectomy (BP-98A, Softron, Tokyo, Japan).

\section{Statistical analysis}

All data are presented as means \pm standard errors of means. Comparison between groups used repeated measurement ANOVA. Differences between groups were compared with a two-sample $t$-test. All statistical assessments were two-tailed and a $p$-value less than 0.05 was considered significant. The significance level was adjusted to $0.0167(0.05 / 3)$ for multiple comparisons between groups for each follow-up time. All statistical analyses were performed using SPSS 15.0 (SPSS Inc, Chicago, IL, USA).

\section{Results}

Changes in body weight, blood pressure, and serum and urine markers

The 36 male Wistar rats were randomly assigned to receive twice daily eplerenone or vehicle (control) 7 days before UUO, and until animal sacrifice on 7 days, 14 days, or 28 days 


\section{Kidney Blood Pressure Research}

Chen/Sun/Zhong/Shao/Yoshimura/Liu: Eplerenone Suppresses Renal Fibrosis

after surgery. The eplerenone and control groups had increasing body weight, decreasing systolic blood pressure, and decreasing diastolic blood pressure over time. However, there were no significant differences between the two groups in these three parameters (Table 1). The calculated mean arterial pressure (MAP) was similar among the two groups at all time points and did not change significantly over the experimental period. The serum and urine analysis results indicate that the serum potassium was significantly lower in the eplerenone group at all sample times and that serum creatinine was significantly lower in the eplerenone group on day-28. There were no significant differences in serum urea nitrogen. On day-7, the control group had a significantly higher level of urinary 8-OHdG, a marker of oxidative stress. These results indicate that any renal protection provided by eplerenone was not related to its effect on blood pressure, but may be related to its reduction of oxidative stress.

\section{Changes in renal histomorphology}

The kidneys of rats subjected to UUO develop conspicuous tubulointerstitial injury that has characteristic tubular dilatation and atrophy, interstitial inflammation, and marked interstitial fibrosis. Examination of the renal tissue of our rats by Masson staining indicated that the glomeruli and vessels were well preserved. The percentage of fibrotic tissue increased in both groups over time, but the eplerenone group had a slower increase and less fibrosis at all sample times (Table 1). Figure 1 shows representative Masson staining results of samples from the eplerenone group and control group. These results indicate that eplerenone treatment suppresses interstitial fibrosis in our UUO rat model.

\section{Changes in expression of markers of inflammation and renal injury}

We performed immuno-staining experiments to examine the mechanism of eplerenone in protection against renal fibrosis (Table 1). Normal kidneys have few macrophages, low expression of MCP-1 (a marker of renal injury), low expression of PCNA (a marker of DNA damage), and low expression of $\alpha$-SMA (a marker of myofibroblast formation). Our results indicate that all 4 markers had lower expression in the eplerenone group than in the control group at all sample times (Table 1 ). Figure 2 shows representative immuno-staining results of samples from the eplerenone group and control group on different days for each of these 4 markers.

Correlation of Masson staining results and potassium level with inflammatory markers

Finally, we analyzed the correlations of Masson staining results and potassium level with inflammatory markers (Table 2). Separate analysis of the eplerenone and control groups indicated no significant correlation between Masson staining results and inflammatory markers or between potassium and inflammatory markers within each group (data not shown). Hence, we presented correlation analysis for all patients on each follow-up day. The results indicated that Masson staining had a significant positive correlation with all five inflammatory markers on day 7, day 14, and day 28 and that potassium had a significant positive correlation with ED-1 on day 7 and with MCP-1, PCNA, and $\alpha$-SMA on day 28.

\section{Discussion}

We used a rat model of renal interstitial fibrosis to study the mechanism of aldosterone blockade in the prevention of renal injury by comparing an eplerenone treatment group with a control group. The results indicate that eplerenone reduced the development of interstitial fibrosis, but had no significant effect on systolic or diastolic blood pressure relative to the control. In particular, histological examination of renal tissues indicated significantly more fibrotic tissue in the control group than in the eplerenone group on day-7 and on all sample times thereafter. Our immuno-staining results indicated that eplerenone also reduced renal inflammation, interstitial cell proliferation, activation of interstitial cells, and oxidative 


\section{Kidney Blood Pressure Research}

Table 1. Body weight, blood pressure, immuno-staining results, Masson staining results, and serum and urine analysis of the eplerenone and control groups on 7, 14, and 28 days after unilateral ureteral obstruction ( $\mathrm{n}=6$ for each group)

\begin{tabular}{|c|c|c|c|c|}
\hline & \multicolumn{3}{|c|}{ Time (day) } & \multirow[b]{2}{*}{$P$ value } \\
\hline & 7 & 14 & 28 & \\
\hline \multicolumn{5}{|c|}{ Characteristic } \\
\hline \multicolumn{5}{|c|}{ Body weight (g) } \\
\hline Eplerenone & $174.67 \pm 7.76$ & $199.67 \pm 6.86$ & $252.83 \pm 18.81$ & 0.180 \\
\hline Control & $176.50 \pm 5.43$ & $205.50 \pm 7.69$ & $274.00 \pm 19.44$ & \\
\hline \multicolumn{5}{|l|}{ SBP (mmHg) } \\
\hline Eplerenone & $122.67 \pm 14.39$ & $117.67 \pm 14.40$ & $110.17 \pm 13.73$ & 0.226 \\
\hline Control & $119.33 \pm 10.48$ & $128.5 \pm 17.31$ & $113.67 \pm 15.85$ & \\
\hline \multicolumn{5}{|l|}{ DBP (mmHg) } \\
\hline Eplerenone & $65.00 \pm 11.01$ & $64.50 \pm 24.88$ & $57.83 \pm 16.19$ & 0.263 \\
\hline Control & $69.17 \pm 15.46$ & $68.67 \pm 11.41$ & $70.00 \pm 20.48$ & \\
\hline MAP (mmHg) & & & & 0.251 \\
\hline Eplerenone & $84.22 \pm 10.74$ & $82.22 \pm 20.90$ & $75.28 \pm 14.23$ & \\
\hline Control & $85.89 \pm 12.70$ & $88.61 \pm 12.36$ & $84.56 \pm 17.74$ & \\
\hline \multicolumn{5}{|c|}{ Immunostaining } \\
\hline \multicolumn{5}{|c|}{ ED-1 (cells $/ 0.5 \mathrm{~mm}^{2}$ ) } \\
\hline Eplerenone & $4.95 \pm 1.23 \dagger$ & $5.07 \pm 1.07 \dagger$ & $6.09 \pm 0.67 \dagger$ & $<.001^{*}$ \\
\hline Control & $7.21 \pm 1.22$ & $7.80 \pm 1.22$ & $11.35 \pm 3.53$ & \\
\hline \multicolumn{5}{|l|}{ MCP-1 (\%) } \\
\hline Eplerenone & $2.44 \pm 0.22 \dagger$ & $13.87 \pm 0.92 \dagger$ & $16.03 \pm 0.84 \dagger$ & $<.001^{*}$ \\
\hline Control & $19.86 \pm 5.92$ & $30.34 \pm 2.09$ & $26.45 \pm 3.48$ & \\
\hline \multicolumn{5}{|c|}{ PCNA (cells $/ 0.5 \mathrm{~mm}^{2}$ ) } \\
\hline Eplerenone & $12.16 \pm 1.43 \dagger$ & $9.10 \pm 1.78 \dagger$ & $5.81 \pm 0.9 \dagger$ & $<.001^{*}$ \\
\hline Control & $23.44 \pm 5.92$ & $13.35 \pm 2.03$ & $13.09 \pm 3.41$ & \\
\hline \multicolumn{5}{|l|}{$\alpha$-SMA (\%) } \\
\hline Eplerenone & $4.69 \pm 0.85 \dagger$ & $5.17 \pm 0.62 \dagger$ & $2.66 \pm 0.34 \dagger$ & $<.001^{*}$ \\
\hline Control & $16.65 \pm 7.2$ & $14.60 \pm 2.3$ & $8.22 \pm 0.74$ & \\
\hline \multicolumn{5}{|c|}{ Masson staining } \\
\hline \multicolumn{5}{|c|}{ Masson (\%) } \\
\hline Eplerenone & $5.78 \pm 0.56 \dagger$ & $9.48 \pm 0.73 \dagger$ & $9.79 \pm 2.64 \dagger$ & $<.001^{*}$ \\
\hline Control & $11.04 \pm 0.73$ & $12.53 \pm 0.77$ & $21.17 \pm 1.65$ & \\
\hline \multicolumn{5}{|c|}{ Serum and Urine analysis } \\
\hline \multicolumn{5}{|c|}{ Potassium (mEQ/L) } \\
\hline Eplerenone & $5.10 \pm 0.27$ & $5.30 \pm 0.63$ & $5.30 \pm 0.34$ & $0.025^{*}$ \\
\hline Control & $5.60 \pm 0.53$ & $5.50 \pm 0.46$ & $5.65 \pm 0.41$ & \\
\hline \multicolumn{5}{|c|}{ Creatinine (mg/dL) } \\
\hline Eplerenone & $0.34 \pm 0.02$ & $0.48 \pm 0.29$ & $0.35 \pm 0.02 \dagger$ & 0.653 \\
\hline Control & $0.35 \pm 0.03$ & $0.35 \pm 0.02$ & $0.42 \pm 0.03$ & \\
\hline \multicolumn{5}{|c|}{ Urea nitrogen $(\mathrm{mg} / \mathrm{dL})$} \\
\hline Eplerenone & $29.38 \pm 4.04$ & $29.75 \pm 6.73$ & $28.55 \pm 2.68$ & 0.423 \\
\hline Control & $32.18 \pm 2.39$ & $28.85 \pm 2.15$ & $29.65 \pm 2.06$ & \\
\hline \multicolumn{5}{|c|}{ 8-ohdg (ng/mL) } \\
\hline Eplerenone & $7.45 \pm 5.51 \dagger$ & ND & ND & ND \\
\hline Control & $11.44 \pm 8.54$ & ND & ND & \\
\hline
\end{tabular}

Each value is the mean \pm standard error of mean. Changes over time were compared between groups using repeated measurement ANOVA; differences between groups for each time were compared using a two-sample $t$-test.

*, significant difference over time between groups $(p<0.05)$

$\dagger$, significant difference between groups at an individual sample time $(p<0.0167)$

Abbreviations: MAP, mean arterial blood pressure ([(2×DBP)+SBP]/3); ED-1, ectodermal dysplasia-1 (macrophage marker); MCP-1, monocyte chemoattractant protein-1 (renal injury marker); PCNA, proliferating cell nuclear antigen (DNA damage marker); $\alpha$-SMA, alpha smooth muscle actin (fibroblast marker); 8-OHdG: 8-hydroxy-2' deoxyguanosine (oxidative damage marker); ND, not determined 


\section{Kidney Blood Pressure Research}

\section{Kidney Blood Press Res 2013;37:557-566}

\begin{tabular}{l|l}
\hline DOI: 10.1159/000355736 & C 2013 S. Karger AG, Basel
\end{tabular}

Published online: November 26, 2013

Chen/Sun/Zhong/Shao/Yoshimura/Liu: Eplerenone Suppresses Renal Fibrosis

Fig. 1. Representative Masson staining results of rats treated with eplerenone and control rats on day-28.
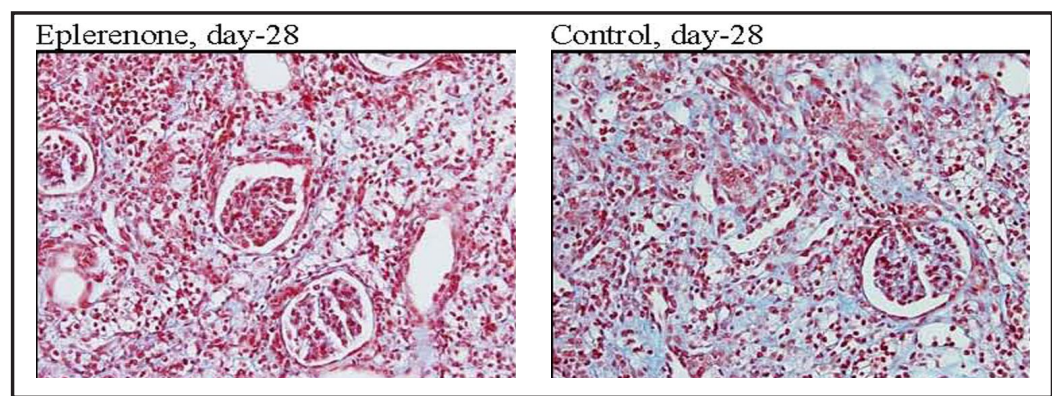

Fig. 2. Representative immuno-staining results of rats treated with eplerenone (left) and control rats (right).

ED-1, control, day-28

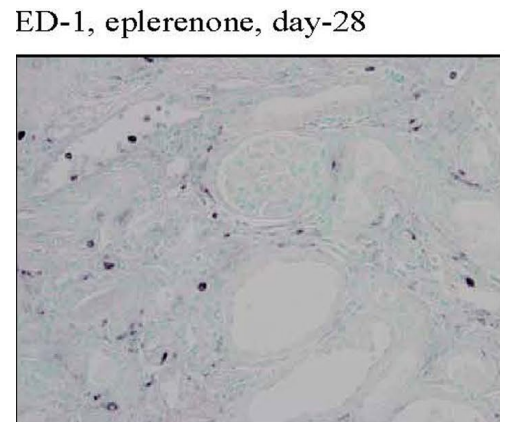

MCP-1, eplerenone, day-14

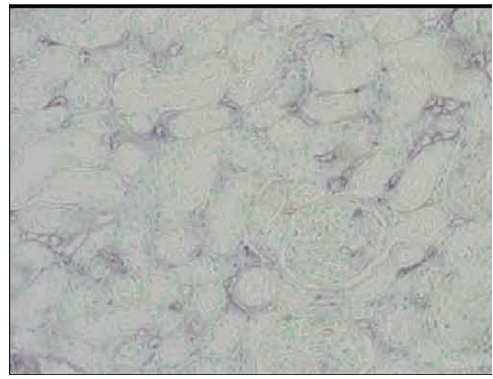

PCNA, eplerenone, day-14

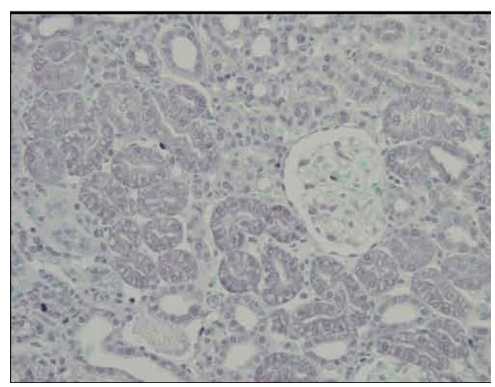

$\alpha$-SMA, eplerenone, day-7

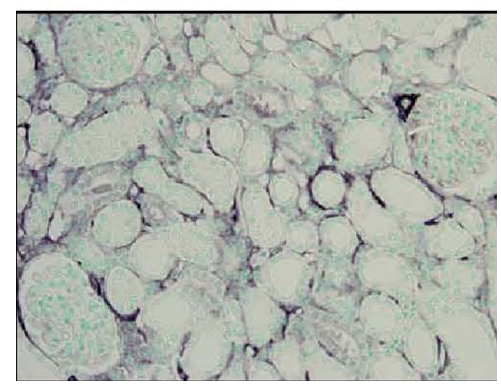

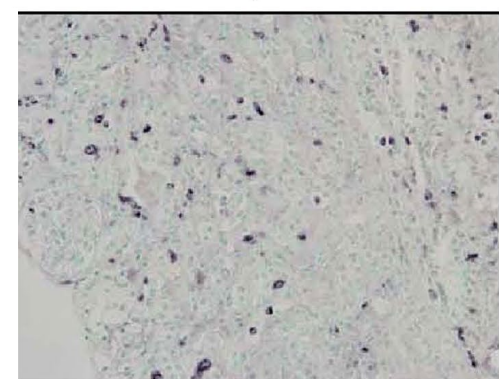

MCP-1, control, day-14

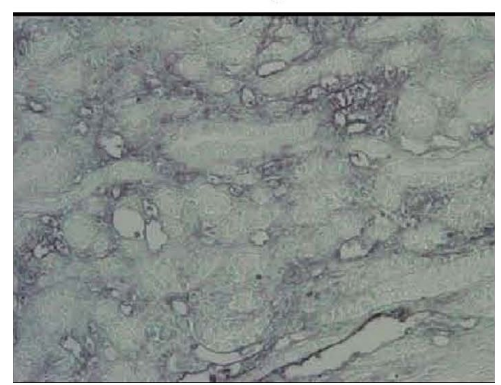

PCNA, control, day-14

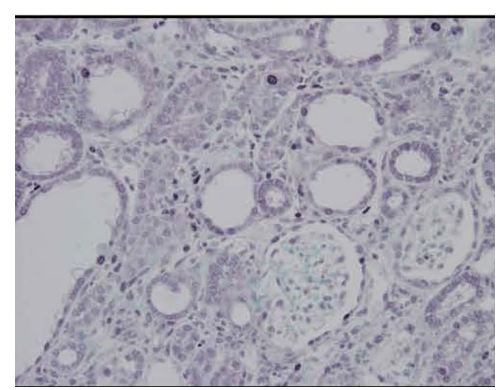

$\alpha$-SMA, control, day-7

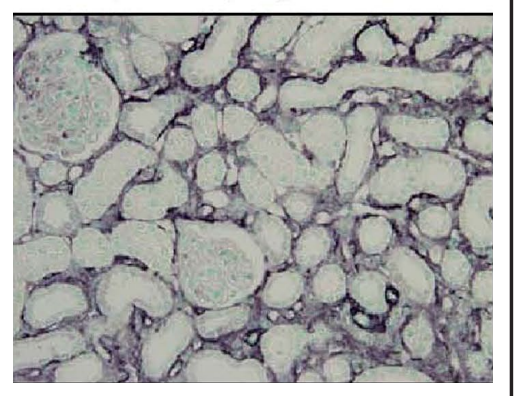




\section{Kidney \\ Blood Pressure Research}

Chen/Sun/Zhong/Shao/Yoshimura/Liu: Eplerenone Suppresses Renal Fibrosis

Table 2. Correlation of Masson staining results and potassium level with inflammatory markers among all patients (eplerenone group + control group) on day 7, day 14, and day 28

\begin{tabular}{|c|c|c|c|c|c|}
\hline \multirow[b]{2}{*}{ Time } & & \multicolumn{2}{|c|}{ Masson(\%) } & \multicolumn{2}{|c|}{ Potassium(mEQ/L) } \\
\hline & & $r$ & $\mathrm{p}$-value & $\mathrm{r}$ & p-value \\
\hline \multirow[t]{4}{*}{ Day 7} & ED-1 (cells $/ 0.5 \mathrm{~mm}^{2}$ ) & 0.659 & $0.020^{*}$ & 0.738 & $0.006^{*}$ \\
\hline & MCP-1 (\%) & 0.914 & $<.001 *$ & 0.524 & 0.080 \\
\hline & PCNA (cells $/ 0.5 \mathrm{~mm}^{2}$ ) & 0.794 & $0.002^{*}$ & 0.410 & 0.185 \\
\hline & $\alpha-\operatorname{SMA}(\%)$ & 0.702 & $0.011^{*}$ & 0.421 & 0.173 \\
\hline \multirow[t]{4}{*}{ Day 14} & ED-1 (cells/0.5mm²) & 0.819 & $0.001^{*}$ & -0.132 & 0.683 \\
\hline & MCP-1 (\%) & 0.867 & $<.001 *$ & 0.159 & 0.621 \\
\hline & PCNA (cells $/ 0.5 \mathrm{~mm}^{2}$ ) & 0.720 & $0.008^{*}$ & 0.282 & 0.375 \\
\hline & $\alpha$-SMA (\%) & 0.901 & $<.001^{*}$ & 0.219 & 0.494 \\
\hline \multirow[t]{4}{*}{ Day 28} & ED-1 (cells $/ 0.5 \mathrm{~mm}^{2}$ ) & 0.685 & $0.014^{*}$ & 0.541 & 0.069 \\
\hline & MCР-1 (\%) & 0.878 & $<.001^{*}$ & 0.751 & $0.005^{*}$ \\
\hline & PCNA (cells $/ 0.5 \mathrm{~mm}^{2}$ ) & 0.807 & $0.001 *$ & 0.718 & $0.009 *$ \\
\hline & $\alpha$-SMA (\%) & 0.915 & $<.001 *$ & 0.758 & $0.004^{*}$ \\
\hline
\end{tabular}

Data indicate coefficient of correlation and corresponding p-values calculated by Pearson correlation analysis. *indicates significantly correlation $(p<0.05)$

stress. Taken together, these results suggest that eplerenone reduces renal interstitial fibrosis at least in part by reducing inflammation, and that this is independent of its effect on haemodynamics.

Other researchers have examined the effects of other mineralocorticoid receptor (MR) antagonists in the UUO model, which has been validated for study of the mechanism and treatment of deterioration of renal function. In particular, Trachtman et al. [21] showed that spironolactone (50 mg/kg SC daily) significantly reduced renal fibrosis in mice with UUO. They suggested that treatment with an aldosterone antagonist with other agents should be considered for renoprotection of patients with obstructive uropathy.

Renal fibrosis is characterized by accumulation of excessive extra-cellular matrix and occurs in numerous chronic kidney diseases. It is necessary to understand the basic pathogenesis of renal fibrosis in order to develop an effective treatment. Aldosterone, which increases renal tubular reabsorption of sodium and secretion of potassium, was classically considered to act on renal epithelial cells. However, recent evidence suggests that aldosterone contributes to cardiovascular and renal disease by promoting fibrosis and inflammation. For example, Epstein [10] reviewed the evidence for aldosterone as a mediator of progressive renal disease and concluded that it is an important factor in progressive renal disease independent of the rennin-angiotensin system. Rocha et al. [12, 22] demonstrated in animal experiments that aldosterone-mediated renal injury developed independently of the increase in blood pressure, suggesting a more direct effect of aldosterone. Several recent studies have confirmed that eplerenone confers renal protection independent of its effects on blood pressure [23, 24]. A recent clinical study [11] compared two different dosages of eplerenone (50 mg and $100 \mathrm{mg}$ ) that were given with an ACE inhibitor to patients with diabetes and albuminuria. Relative to placebo, these low dosages significantly reduced the urinary albumin-to-creatinine ratio and albuminuria but had no effect on blood pressure.

Nielsen et al. [25] studied the effect of eplerenone ( $100 \mathrm{mg}$ PO daily) on renal interstitial fibrosis after prolonged cyclosporine (CsA) treatment in rats. In contrast to our results, their results indicated that eplerenone significantly lowered blood pressure. This may be because (i) their rats received CsA in addition to eplerenone, (ii) their rats received oral eplerenone and our rats received eplerenone by gastric tube, (iii) they measured blood pressure by use of indwelling arterial and venous catheters, and we measured blood pressure by use of tail cuffs. Many previous studies have validated the tail cuff method for measurement of blood pressure [26, 27], so we prefer the first or second explanations. 


\section{Kidney Blood Pressure Research}

Previous studies $[16,22]$ in rat models demonstrated that the renal injury and fibrosis induced by aldosterone infusion were characterized by inflammation, macrophage infiltration, and up-regulation of pro-inflammatory cytokines. In another rat study, Blasi et al. [23] reported that treatment with eplerenone $(100 \mathrm{mg} / \mathrm{kg} /$ day $)$ reduced albuminuria and expression of proinflammatory genes, including MCP-1, interleukin-6, and interleukin-1ß. MCP-1 is one of the most important mediators of the inflammatory process in the kidney [20]. In agreement with these previous studies, we found that UUO led to an increase in the number of inflammatory cells (monocytes and macrophages) in the renal cortex and that eplerenone attenuated this effect. PCNA is a co-factor of DNA polymerase and plays an essential role in the replication and repair of DNA [28]. In the present study, UUO induced a marked increase in the number of PCNA-positive cells, and eplerenone blocked this effect. In addition, there were significant correlations of the Masson staining results with all five inflammatory markers on day 7 , day 14 , and day 28 . This supports the hypothesis that fibrotic damage is related to oxidative stress.

When cytosolic MR binds to aldosterone, it moves to the nucleus, where it binds to hormone response elements and promotes expression of certain genes. A previous study of Dahl salt-sensitive rats indicated that increased oxidative stress promoted activation of the glomerular MR, and that eplerenone effectively restored urinary protein to normal levels [29]. Another study of C57BL/6J mice indicated that obesity and renal injury were associated with increased MR/Rho/Rho-kinase activity and that treatment with eplerenone inhibited these changes [30]. Taken together with other studies [31], it appears that oxidative damage leads to Rac1-induced activation of the MR and that this leads to renal injury. MR from renal distal nephrons or from other cells, such as macrophages, thus appear to be responsible for renal injury by oxidative processes [31].

Alpers et al. [32] reported accumulation of cells expressing SMA at sites of chronic tubulointerstitial injury in allograft and pyelonephritic kidneys. Elevated $\alpha$-SMA expression may reflect activation of fibroblasts to myofibroblasts, which may contribute to the pathophysiology of UUO [33]. Guo et al. [34] studied a murine UUO model and reported that knockout of angiotensin II or TNF-alpha reduced renal fibrosis and decreased $\alpha$-SMA expression. In the present study we found the expression of $\alpha$-SMA was maximal on day 7 after UUO, and that eplerenone significantly reduced interstitial $\alpha$-SMA expression on day 7 and at subsequent sample times. A limitation of this study is that we did not measure urinary 8-OHdg on days 14 and 28. Measurement of 8-OHdg at these additional times would have provided further support for our hypothesis that reduction in fibrosis was related to attenuation of oxidative stress. In addition, measurement of plasma aldosterone may have also provided additional information on the mechanism of the responses that we observed.

Oxidative stress leads to tissue damage due to the excessive generation of oxidants and insufficient defense provided by endogenous anti-oxidant mechanisms [35]. Previous studies have suggested that stimulation of reactive oxygen species production underlies the aldosterone-mediated promotion of renal fibrosis $[17,18]$. Our results indicated that urinary excretion of 8-OHdG, a common in vivo marker for oxidative stress, was elevated in the control group relative to the eplerenone group. This result is consistent with the hypothesis that eplerenone ameliorates renal fibrosis due to its anti-oxidant effect.

\section{Conclusion}

Eplerenone is a competitive antagonist of the aldosterone receptor, a component of the renin-angiotensin-aldosterone-system, and is approved for treatment of hypertension and congestive heart failure post-myocardial infarction. Our results indicate that eplerenone has significant anti-fibrotic effects independent of its effect on blood pressure. These results suggest that eplerenone treatment may provide a new method for suppression of renal interstitial fibrosis. 


\section{Kidney \\ Blood Pressure Research}

Chen/Sun/Zhong/Shao/Yoshimura/Liu: Eplerenone Suppresses Renal Fibrosis

\section{Conflict of Interests}

The authors declare that they have no competing interests.

\section{Acknowledgements}

We are very grateful to all the researchers involved in the experiment. We also thank Showa University Fujigaoka Hospital for technical support. Part of this work has been presented as a poster communication at the $51^{\text {st }}$ Annual Meeting of Japanese Society of Nephrology.

\section{References}

1 Delyani JA: Mineralocorticoid receptor antagonists: The evolution of utility and pharmacology. Kidney Int 2000;57:1408-1411.

Wimett L, Laustsen G: Inspra improves survival for chf patients. Nurse Pract 2004;29:56-59.

Weinberger MH, Roniker B, Krause SL, Weiss RJ: Eplerenone, a selective aldosterone blocker, in mild-tomoderate hypertension. Am J Hypertens 2002;15:709-716.

-4 Pitt B, Remme W, Zannad F, Neaton J, Martinez F, Roniker B, Bittman R, Hurley S, Kleiman J, Gatlin M: Eplerenone, a selective aldosterone blocker, in patients with left ventricular dysfunction after myocardial infarction. N Engl J Med 2003;348:1309-1321.

5 Krum H, Nolly H, Workman D, He W, Roniker B, Krause S, Fakouhi K: Efficacy of eplerenone added to reninangiotensin blockade in hypertensive patients. Hypertension 2002;40:117-123.

6 Epstein M, Alexander JC, Roniker B: Efficacy and safety of eplerenone, a novel and selective aldosterone receptor antagonist (SARA), in patients with mild to moderate hypertension [Abstract]. Hypertension 1999;33:1075.

7 Cattran DC, Greenwood C, Ritchie S: Long-term benefits of angiotensin-converting enzyme inhibitor therapy in patients with severe immunoglobulin a nephropathy: A comparison to patients receiving treatment with other antihypertensive agents and to patients receiving no therapy. Am J Kidney Dis 1994;23:247-254.

-8 Ishidoya S, Morrissey J, McCracken R, Reyes A, Klahr S: Angiotensin ii receptor antagonist ameliorates renal tubulointerstitial fibrosis caused by unilateral ureteral obstruction. Kidney Int 1995;47:1285-1294.

-9 Rosenberg ME, Smith LJ, Correa-Rotter R, Hostetter TH: The paradox of the renin-angiotensin system in chronic renal disease. Kidney Int 1994;45:403-410.

10 Epstein M: Aldosterone and the hypertensive kidney: Its emerging role as a mediator of progressive renal dysfunction: A paradigm shift. J Hypertens 2001;19:829-842.

-11 Epstein M, Williams GH, Weinberger M, Lewin A, Krause S, Mukherjee R, Patni R, Beckerman B: Selective aldosterone blockade with eplerenone reduces albuminuria in patients with type 2 diabetes. Clin J Am Soc Nephrol 2006;1:940-951.

12 Rocha R, Chander PN, Khanna K, Zuckerman A, Stier CT, Jr.: Mineralocorticoid blockade reduces vascular injury in stroke-prone hypertensive rats. Hypertension 1998;31:451-458.

13 Eddy AA: Interstitial macrophages as mediators of renal fibrosis. Exp Nephrol 1995;3:76-79.

14 Klahr S, Morrissey J: Obstructive nephropathy and renal fibrosis. Am J Physiol Renal Physiol 2002;283:F861-875.

15 Nishida M, Okumura Y, Fujimoto S, Shiraishi I, Itoi T, Hamaoka K: Adoptive transfer of macrophages ameliorates renal fibrosis in mice. Biochem Biophys Res Commun 2005;332:11-16.

16 Rocha R, Funder JW: The pathophysiology of aldosterone in the cardiovascular system. Ann N Y Acad Sci 2002;970:89-100.

17 Stier C Jr., Zuckerman A, Harashima H, Chander P: Antioxidants reduce aldosterone-induced renal vascular injury in stroke-prone spontaneously hypertensive rats [Abstract]. Proc Int Soc Hypertens 2000; P4.03. 


\section{Kidney \\ Blood Pressure Research}

Kidney Blood Press Res 2013;37:557-566

\begin{tabular}{l|l}
\hline DOI: $10.1159 / 000355736$ & (C) 2013 S. Karger AG, Basel
\end{tabular}

Published online: November 26, 2013

www.karger.com/kbr

18 Fujihara CK, Malheiros DM, Zatz R, Noronha IL: Mycophenolate mofetil attenuates renal injury in the rat remnant kidney. Kidney Int 1998;54:1510-1519.

19 Jepsen FL, Mortensen PB: Interstitial fibrosis of the renal cortex in minimal change lesion and its correlation with renal function. A quantitative study. Virchows Arch A Pathol Anat Histol 1979;383:265270.

20 Vieira JM, Jr., Mantovani E, Rodrigues LT, Delle H, Noronha IL, Fujihara CK, Zatz R: Simvastatin attenuates renal inflammation, tubular transdifferentiation and interstitial fibrosis in rats with unilateral ureteral obstruction. Nephrol Dial Transplant 2005;20:1582-1591.

-21 Trachtman H, Weiser AC, Valderrama E, Morgado M, Palmer LS: Prevention of renal fibrosis by spironolactone in mice with complete unilateral ureteral obstruction. J Urology 2004;172:1590-1594.

-22 Rocha R, Chander PN, Zuckerman A, Stier CT, Jr.: Role of aldosterone in renal vascular injury in strokeprone hypertensive rats. Hypertension 1999;33:232-237.

-23 Blasi ER, Rocha R, Rudolph AE, Blomme EA, Polly ML, McMahon EG: Aldosterone/salt induces renal inflammation and fibrosis in hypertensive rats. Kidney Int 2003;63:1791-1800.

24 Zhou X, Ono H, Ono Y, Frohlich ED: Aldosterone antagonism ameliorates proteinuria and nephrosclerosis independent of glomerular dynamics in l-name/shr model. Am J Nephrol 2004;24:242-249.

25 Nielsen FT, Jensen BL, Hansen PB, Marcussen N, Bie P: The mineralocorticoid receptor antagonist eplerenone reduces renal interstitial fibrosis after long-term cyclosporine treatment in rat: Antagonizing cyclosporine nephrotoxicity. BMC Nephrol 2013;14:42.

-26 Feng M, Whitesall S, Zhang Y, Beibel M, D'Alecy L, DiPetrillo K: Validation of volume-pressure recording tailcuff blood pressure measurements. Am J Nephrol 2008;21:1288-1291.

27 Ibrahim J, Berk BC, Hughes AD: Comparison of simultaneous measurements of blood pressure by tail-cuff and carotid arterial methods in conscious spontaneously hypertensive and wistar-kyoto rats. Clin Exp Hypertens 2006;28:57-72.

-28 Kelman Z: Pcna: Structure, functions and interactions. Oncogene 1997;14:629-640.

-29 Kitada K, Nakano D, Liu Y, Fujisawa Y, Hitomi H, Shibayama Y, Shibata H, Nagai Y, Mori H, Masaki T, Kobori H, Nishiyama A: Oxidative stress-induced glomerular mineralocorticoid receptor activation limits the benefit of salt reduction in Dahl salt-sensitive rats. PLoS One 2012;7:e41896.

-30 Tokuyama H, Wakino S, Hara Y, Washida N, Fujimura K, Hosoya K, Yoshioka K, Hasegawa K, Minakuchi H, Homma K, Hayashi K, Itoh H: Role of mineralocorticoid receptor/Rho/Rho-kinase pathway in obesityrelated renal injury. Int J Obes (Lond) 2012;36:1062-1071.

-31 Nagase M, Fujita T: Role of Rac1-mineralocorticoid-receptor signalling in renal and cardiac disease. Nat Rev Nephrol 2013;9:86-98.

-32 Alpers CE, Hudkins KL, Floege J, Johnson RJ: Human renal cortical interstitial cells with some features of smooth muscle cells participate in tubulointerstitial and crescentic glomerular injury. Clin J Am Soc Nephrol 1994;5:201-209.

-33 Zeisberg M, Kalluri R: The role of epithelial-to-mesenchymal transition in renal fibrosis. Int J Mol Med 2004;82:175-181.

-34 Guo G, Morrissey J, McCracken R, Tolley T, Liapis H, Klahr S: Contributions of angiotensin ii and tumor necrosis factor-alpha to the development of renal fibrosis. Am J Physiol Renal Physiol 2001;280:F777-F785.

-35 Sies H: Oxidative stress: Oxidants and antioxidants. Exp Physiol 1997;82:291-295. 